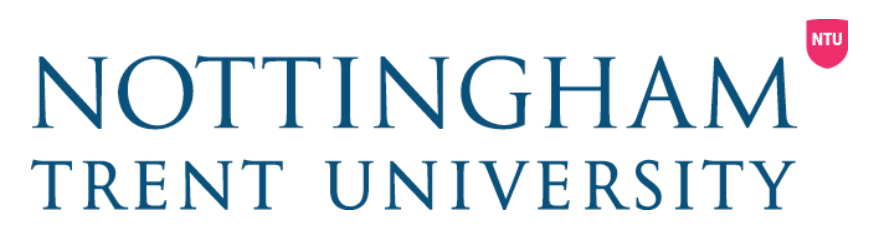

DISCUSSION PAPERS

\author{
I $\mathbf{N}$ \\ ECONOMICS
}

No. 2008/ 6 ISSN 1478-9396

ENTREPRENEURSHI P AND UNEMPLOYMENT: A NONLI NEAR BI DI RECTI ONAL CAUSALITY?

J oão Ricardo FARI A, J uan Carlos CUESTAS and Estefanía MOURELLE 


\section{DISCUSSI ON PAPERS IN ECONOMICS}

The economic research undertaken at Nottingham Trent University covers various fields of economics. But, a large part of it was grouped into two categories, Applied Economics and Policy and Political Economy.

This paper is part of the new series, Discussion Papers in Economics.

Earlier papers in all series can be found at:

http://www.ntu.ac.uk/research/school_research/nbs/overview/working_papers/index .html

Enquiries concerning this or any of our other Discussion Papers should be addressed to the Editor:

Dr Juan Carlos Cuestas

Division of Economics

Nottingham Trent University

Burton Street

Nottingham, NG1 4BU

UNITED KINGDOM

Email: juan.cuestas@ntu.ac.uk 


\title{
Entrepreneurship and unemployment: A nonlinear bidirectional
}

\author{
causality?
}

\author{
João Ricardo Faria \\ IPED, University of Texas El Paso, USA \\ Juan Carlos Cuestas* \\ Nottingham Business School, Nottingham Trent University, UK \\ Estefanía Mourelle \\ Facultad de Ciencias Económicas y Empresariales, Universidade da Coruña, Spain
}

\begin{abstract}
This paper tests the view that the relation between unemployment and entrepreneurship is dynamic and possibly nonlinear. It performs Grangercausality tests and STAR-EXT estimation to assess the causality direction and the nonlinear nature of the relation for a set of OECD countries. The results reveal a bidirectional and nonlinear relation between business creation and changes in unemployment.
\end{abstract}

Keywords: New firms; employment creation; causality; nonlinearities; STAR-EXT.

JEL Classification: J69, L26, M13

*Corresponding author: J.C. Cuestas, Nottingham Business School, Nottingham Trent University, NG1 4BU, United Kingdom. Phone +44(0) 115848 4328; fax: +44(0) 115848 4707. E-mail: juan.cuestas@ntu.ac.uk. Juan Carlos Cuestas gratefully acknowledges the financial support from the CICYT and FEDER project SEJ2005-01163, the Bancaja project P1.1B2005-03 and the Generalitat Valenciana Complementary Action ACOMP07/102. Juan Carlos Cuestas is a member of the INTECO research group. The usual disclaimer applies. 


\title{
Entrepreneurship and unemployment: A nonlinear bidirectional
}

\author{
causality?
}

\section{Introduction}

Entrepreneurship is one of the main engines of growth in modern economies [e.g., Thurik, 2008]; as a consequence, its role in impacting unemployment is of utmost importance. Empirical studies have shown that small businesses have become more important over the past recent decades. During most part of the $20^{\text {th }}$ century, however, large firms occupied the main role in the economy [e.g., Caves, 1982], when economies of scale seemed to be the decisive factor ${ }^{1}$.

The evidence that the relative importance of small businesses was declining over time [Scherer, 1991] became a stylized fact. This triggered a massive and influential literature concerning small business in post-war developed economies to establish other stylized facts, such as: i) Small businesses are generally less efficient than larger firms [Pratten, 1971]; ii) Small business have lower level of employee compensation [Brown and Medoff, 1989]; iii) Small businesses are marginally innovative [Chandler, 1990].

This scenario changed in the last decades of the twentieth century due, among other factors, to economic instability, technological innovations and globalization. Economic activity moved away from large firms to small firms in the 1970's and 1980's [Carlsson, 1992; and Acs and Audretsch, 1993]. According to Carlsson (1992) globalization fostering greater competition, uncertainty and market fragmentation, on the one hand, and technological progress, on the other hand, played important roles in

\footnotetext{
${ }^{1}$ This helps explain the shift of Schumpeter's view of entrepreneurs. In his Theory of Economic Development, published in 1908, he emphasized creative destruction led by individual entrepreneurs, while in his Capitalism, Socialism and Democracy, published in 1942, he focuses on innovative activities by large firms, a process of creative accumulation. In Galbraith's famous book (1956) this is the world of big business that is balanced by big government and big labor.
} 
this change. Brock and Evans (1989) identify four reasons for the change: increase of labor supply, changes in consumer tastes, relaxation of regulations and the fact that the world economy was under a creative destruction period.

Globalization has shifted comparative advantage of high cost location to knowledge-based activities with high cost transfer, leading to the re-emergence of the entrepreneurial economy [e.g., Audretsch and Thurik, 2000, 2001 and 2004]. Audretsch and Thurik (2007) characterize the entrepreneurial economy as an economy with greater flexibility, turbulence, diversity, creativity, and novelty.

In an entrepreneurial economy entrepreneurship is one of the engines of growth. As economic growth is linked to changes in unemployment, through the growth rate form of the Okun's law [e.g. Prachowny, 1993], one can safely assume that there is a relation between entrepreneurship and unemployment. However, what type of relationship is this? Should we expect that greater entrepreneurial activity leads to greater economic growth and, as a consequence, lower unemployment rates? In this case entrepreneurship causes a reduction in unemployment, and as a result there is an inverse relationship between them; more entrepreneurship, less unemployment.

It is important to stress that the economic growth channel as exposed above is just one of the possible ways to link entrepreneurship with unemployment. There are other alternatives, not necessarily opposed to the economic growth channel, worth noticing. The pioneering work of Oxenfeldt (1943), for example, extended Frank Knight's (1921) view that individuals choose between unemployment, self-employment and employment, by taking into account relative prices of these activities. In this sense, unemployed individuals facing low prospects of wage employment, turn to selfemployment as the best alternative. Therefore, unemployment is positively related to business creation. Another approach to address the relationship is given by the Gibrat's 
law literature. The Gibrat's law says that firm growth is independent of size [e.g., Sutton, 1997], which implies that when the economy change from large corporations to small firms the unemployment rate should not change ${ }^{2}$.

It is well known that the link between unemployment and entrepreneurship is a relevant empirical relationship that, so far, is characterized by ambiguity. Some studies have found that entrepreneurship and unemployment are inversely related, but others have come to the opposite conclusion, finding that unemployment is associated with greater entrepreneurial activities. For instance, Garofoli (1994) and Audretsch and Fritsch (1994) found that unemployment is negatively related to new-firm startups, while Highfield and Smiley (1987) and Evans and Leighton (1990) found that unemployment is positively associated with a greater propensity to start a new firm.

The ambiguity showed by the empirical work has led researchers to postulate that the relation between entrepreneurship and unemployment is dynamic, as in Audretsch et al. (2001). It also may be the case that the dynamic relation is nonlinear, possibly cyclical, as found by Faria et al. (2008). It is important to emphasize that the dynamic and nonlinear nature of the relationship does not necessarily contrast with the views exposed above; it may push the proponents of the above cited literature to consider the feedback mechanisms derived from their views on the relationship between entrepreneurship and unemployment.

This paper contributes to this line of research by assessing the Granger-causality between entrepreneurship and unemployment for a set of OECD countries. It also studies whether or not there is some nonlinear causality between them, based on a smooth transition autoregression with exogenous transition (STAR-EXT) estimation. The paper is organized as follows. The next section presents the Granger causality tests.

\footnotetext{
${ }^{2}$ For Geroski (1995) it is a stylized fact that smaller firms have higher growth rates than their larger counterparts.
} 
The nonlinear modeling appears in section 3. Finally, section 4 presents the concluding remarks.

\section{Granger causality results}

The data for our empirical application consist of two variables; unemployment rates $\left(u_{t}\right)$ and self employment (business ownership per labor force) $\left(\mathrm{e}_{t}\right)$. We have selected a small sample of OCDE countries in order to carry out the empirical analysis, i.e. Australia, Japan, United States, United Kingdom, Republic of Ireland, Germany, France, Italy and Spain, with annual observations from 1972 to 2004 . The data have been obtained from the Comparative Entrepreneurship Data for International Analysis (COMPENDIA) data base.

First, we have applied the $\mathrm{Ng}$ and Perron (2001) unit root tests in order to analyze the order of integration of both variables. $\mathrm{Ng}$ and Perron (2001) propose several unit root tests that are modifications of existing ones in order to improve their performance, i.e. size and power, in particular in short sample sizes. The results indicate that both variables are unit root processes ${ }^{3}$. Note that if the variables are integrated processes, the variable business creation (the differential between actual business ownership and its past values) as well as the variation in unemployment are stationary. Therefore, the empirical analysis is going to rely on the estimation of a VAR model in first differences and testing for Granger causality.

Table 1 displays the results for the Granger causality test. The lag length has been selected using the Schwartz Information Criteria (SIC) from a maximum of 8 lags. In order to compute the variables of business creation $\Delta^{i} e_{t}=e_{t}-e_{t-i}$ and variation in unemployment $\Delta^{i} u_{t}=u_{t}-u_{t-i}$ we have used a time span $i$ larger than one year, since

\footnotetext{
${ }^{3}$ Although the results have been omitted in the present paper, they are available upon request.
} 
the impact of new startups on unemployment, and vice versa, is not instantaneous and it requires some time [Audretsch et al., 2001]. This means that for the new unemployed obtaining the necessary resources to open a new firm, and for new firms to grow enough in order to be able to hire new workers, it is necessary more than one year.

From table 1 it is possible to highlight the fact that for the countries analyzed, except for the $\mathrm{UK}^{4}$, where we could not find any causality between unemployment variation and business for different spans of time, there is a causal relationship between business creation and variation in unemployment. It is noticeable that for some of the countries, such as Ireland, Germany, United States and Australia (probably the countries with the most dynamic labor markets from our sample), the null hypothesis of no causation is rejected in both directions, implying then that the direction of causality is bilateral. For the rest of the cases, we only find that unemployment variation cause business creation in Italy and Japan. Finally, in the case of France, the causation runs from entrepreneurship to unemployment.

\section{INSERT TABLE 1 HERE}

\section{Nonlinearities in causation. Methodology and results}

In this section, the analysis goes beyond the linear causal relationship in order to detect whether nonlinear effects are the underlying factors explaining causality and, therefore, the reason why Granger tests failed for some countries.

The existence of nonlinearities would mean that variation in unemployment rates (business creation) behaves in a different manner depending on the state given by business creation (variation in unemployment rates). This asymmetric behavior will be

\footnotetext{
${ }^{4}$ Result available upon request to the authors.
} 
captured through the STAR-EXT model, a type of smooth transition (ST) specification. Thus, this paper investigates and assesses the performance of STAR-EXT models compared to that of linear specifications in reflecting the causation between unemployment and entrepreneurship.

\section{The model}

STs belong to the family of state-dependent models. The data generating process is a linear one that switches between a certain number of regimes according to some rule; the regime is characterized as a continuous function of a predetermined variable, so that interactions between variables, as well as intermediate states between the extreme regimes, are permitted. We choose this parameterization because it allows for a variety of dynamic behavior that a linear model cannot characterize in an appropriate way and, moreover, once the state is given, the model is locally linear and easy to interpret. See Granger and Teräsvirta (1993), Teräsvirta (1994, 1998) and van Dijk et al. (2002) for a further insight of STs.

The model to be used in this paper is a basic version of ST models: the smooth transition autoregression (STAR). This specification implies a univariate dynamic dependence and an endogenous regime determination. For this purpose, an exogenous transition is needed and the solution is given by the STAR-EXT models proposed in Cancelo and Mourelle (2005); these models are midway between STARs and general smooth transition regressions.

Suppose $\left\{\mathrm{y}_{\mathrm{t}}\right\}$ a stationary, ergodic process: the STAR-EXT model of order $\mathrm{p}$ with $\mathrm{x}_{\mathrm{t}}$ the exogenous variable is defined as 


$$
y_{t}=\pi_{0}+\sum_{i=1}^{p} \pi_{i} y_{t-i}+F\left(x_{t-d}\right)\left[\theta_{0}+\sum_{i=1}^{p} \theta_{i} y_{t-i}\right]+u_{t}
$$

where $\mathrm{F}\left(\mathrm{x}_{\mathrm{t}-\mathrm{d}}\right)$ is a transition function customarily bounded between 0 and 1 that makes the STAR-EXT coefficients vary between $\pi_{j}$ and $\pi_{j}+\theta_{j}(j=0, \ldots, p)$, respectively; $d$ is the transition lag. The regime at each $\mathrm{t}$ is determined by the transition variable, $\mathrm{x}_{\mathrm{t}-\mathrm{d}}$, and the associated value of $F\left(x_{t-d}\right)$. In its basic version, the regime-switching STAR model considers two distinct regimes, corresponding to $\mathrm{F}=0$ and $\mathrm{F}=1$; the transition from one regime to the other is smooth over time, meaning that parameters in (1) gradually change with the state variable.

The STAR model links two linear components through $\mathrm{F}($.$) , so that connection$ features depend on the formulation for F, especially on whether it is odd or even. The odd case is usually represented by the logistic function:

$$
F\left(x_{t-d}\right)=\frac{1}{1+\exp \left[-\gamma\left(x_{t-d}-c\right)\right]}, \quad \gamma>0
$$

The resulting model is the Logistic STAR-EXT or LSTAR-EXT model, where $\mathrm{F}(-\infty)=0$ and $\mathrm{F}(\infty)=1$. The slope parameter $\gamma$ defines the smoothness of the transition from one regime to the other: the greater it is the more rapid the change. The location parameter $\mathrm{c}$ indicates the threshold between the two regimes; here, $\mathrm{F}(\mathrm{c})=0.5$, so the regimes are associated with low and high values of $\mathrm{x}_{\mathrm{t}-\mathrm{d}}$ relative to $\mathrm{c}$.

Second, the exponential function

$$
F\left(x_{t-d}\right)=1-\exp \left[-\gamma\left(x_{t-d}-c\right)^{2}\right\rfloor, \quad \gamma>0
$$

provides the Exponential STAR-EXT (ESTAR-EXT) model. This even function implies $F( \pm \infty)=1$ and $F(c)=0$ for some finite $c$, defining the outer and the middle extreme regime, respectively. 
The selection of the transition function is a key point for understanding nonlinearities since logistic and exponential models describe quite different types of (regime-switching) behavior. In the LSTAR-EXT model the extreme regimes are associated with $\mathrm{x}_{\mathrm{t}-\mathrm{d}}$ values far above or below $\mathrm{c}$, where dynamics may be different; the ESTAR-EXT model suggests a rather similar dynamics in the extreme regimes, related to low and high $\mathrm{x}_{\mathrm{t}-\mathrm{d}}$ absolute values, while it can be different in the transition period.

\section{Modeling procedure}

The first step is to determine the linear model that would describe the evolution of variation of unemployment and business creation in the countries. We carry out an ordinary least squares estimation, considering a range of values for the lag order $p$ from 1 to 6 (a sixth-order dynamics seems general enough for annual data); we use the Akaike Information Criterion (AIC) to select the proper number of lags in each case. To save space, linear models are not reported, but they are available from the authors upon request.

The next step is the specification and estimation of the STAR-EXT models for all countries; we regard the causality running from business creation to variation of unemployment and vice versa.

Traditionally, the modeling cycle for ST(A)R models has had its basis on reproducing Box and Jenkins (1970) iterative methodology with the development of the following stages: search for specification, estimation and evaluation of the model. There exists a well-established ST(A)R modeling strategy in the literature [Granger and Teräsvirta, 1993; Teräsvirta, 1994]. Nonetheless, the most recent empirical work does not follow this procedure in such a strict manner; it is argued that it is possible to 
develop valid nonlinear formulations that improve the fit of the linear ones by means of an extensive search of ST(A)R models (even if the null hypothesis of linearity is not rejected). This is the methodology considered in this paper.

We define several combinations of $\mathrm{p}, \mathrm{d}$ and $\mathrm{F}($.$) : the transition lag varies from 0$ to $\mathrm{p}$ and the transition function is permitted to be either logistic or exponential. As a result, a large number of potential models are specified; the one offering the best properties is selected. This process follows the one traced by Öcal and Osborn (2000), van Dijk et al. (2002) and Sensier et al. (2002), among others. It departs from the commonly used Teräsvirta's (1994) procedure in that lesser emphasis is laid on the early stages of the modeling process in exchange for attaching more importance to the evaluation of the finally proposed model, so that any possible inadequacy of the nonlinear model is expected to be unveiled at the evaluation stage.

STAR-EXT specifications are estimated by nonlinear least squares. The key point is the estimation of the slope parameter and the location parameter, as they can pose special problems like those reported in Teräsvirta (1994). Following the recommendations of this author, the argument of the transition function is scaled by dividing it by the standard deviation of the dependent variable in the logistic case and by the variance in the exponential one. We have tried several values for $\gamma$ and a value close to the sample mean of the transition variable for $\mathrm{c}$.

The best models are subject to further refinement. First, nonsignificant coefficients are excluded to conserve degrees of freedom; then, we simplify this first set of estimations through cross-parameter restrictions in order to increase efficiency. We take 1.6 as the limit $\mathrm{t}$-value for these coefficients.

Finally, several misspecification tests to validate the proposed models are developed. We consider the test of no autoregressive conditional heteroskedasticity with 
four lags $(\mathrm{ARCH})$ and the test of business cycle heteroskedasticity $(\mathrm{BCH})$ posed by Öcal \& Osborn (2000). There are three tests specially derived for smooth transition models in Eitrheim \& Teräsvirta (1996) that we also report: the test of residual serial independence against process of different orders, although just the correspondent to order 6 is shown (AUTO); the test of no remaining nonlinearity in the residuals, computed for several values of the transition lag under the alternative but only the one minimizing the p-value of the tests is displayed (NL); the test of parameter constancy that allows for monotonically changing parameters under the alternative (PC).

Likewise, we also pay attention to the significance of the estimated coefficients, the characteristics of the transition function and the results of the following diagnostic statistics: the residual standard error (s), the adjusted determination coefficient $\left(\bar{R}^{2}\right)$ and the variance ratio of the residuals from the nonlinear model and the best linear specification $\left(\mathrm{s}^{2} / \mathrm{s}_{\mathrm{L}}^{2}\right)$.

\section{Empirical results}

The extensive search of STAR-EXT models generates multiple STR specifications, although parameter convergence is not attained in some of them. The estimation process is developed for both directions of causality: from entrepreneurship to unemployment and vice versa. Beginning with the first one, empirical evidence reveals that business creation causes nonlinear effects on unemployment variation. This behavior is reflected in the STAR-EXT models presented in table 2, together with some diagnostic and evaluation statistics.

INSERT TABLE 2 HERE 
In addition to this, the linearity hypothesis is tested against the estimated STAREXT models; table 3 displays the p-values of the $\mathrm{F}$ tests and evidence of nonlinear behavior is founded in all countries at a 0.10 significance level (United Kingdom is on the edge).

\section{INSERT TABLE 3 HERE}

The estimated regression coefficients are significant and above 1 in several cases, reflecting a considerable dynamism in the variation of unemployment; lag order $p$ is moderate, so recent history of unemployment variation has effects on its current state for a (reasonable) long time. The transition from one regime to the other is not very fast and location parameter values are reasonably close to business creation sample means in most of the countries, so that a near equal distribution between the left and the right sides of the exponential function is expected. Italy clearly shows the opposite case, with the majority of the observations lying to the right of $\mathrm{c}$; therefore, this exponential function in practice behaves as a logistic one.

There is no evidence of misspecification in the models, so they seem to be adequate. A fact to emphasize is the high explanatory power of the nonlinear models compared to the linear autoregressions, according to the variance ratios: the STAR-EXT model explains $14 \%$ to $61 \%$ of the residual variance of the best linear autoregression in all nine countries.

In short, variation in unemployment displays an asymmetric response depending on how business creation evolves. As the transition between regimes is exponential in all countries (see figure 1), the dynamics of variation in unemployment rates are similar when business creation is either very high or very low (outer regime), but different for an "intermediate" situation, that is, close to its mean (middle regime).

\section{INSERT FIGURE 1 HERE}


The fact of mainly having encountered exponential transitions may be related to the dynamic interaction existent between entrepreneurship and unemployment, described by limit cycles, as Faria et al. (2008) prove. Thus, for instance, a state of severe business creation needs hiring workers (reduction in unemployment), but a greater competition is also generated, leading to a smaller firm creation and to a potential increase in unemployment; the opposite situation takes place for a poor business creation, where the result may also be either an increase or a decrease in unemployment. These situations would correspond to the outer regime, where we appreciate rather similar dynamics in unemployment variation. Different dynamics arises in the middle regime: the growth in unemployment behaves in a different manner when business creation is near its average value.

Information about the local dynamic properties of the estimated nonlinear models can be obtained from the roots of the characteristic polynomials associated to them. In this paper, we compute the roots for the two extreme values of the transition function, $\mathrm{F}=0$ and $\mathrm{F}=1$; in order to save space, table 4 only displays the root with the highest modulus that is determining the long-run behavior of the series within each regime, i. e., the dominant root.

\section{INSERT TABLE 4 HERE}

The estimated models are globally stationary although locally unstable in five over nine countries. Australia, United States, Ireland, France and Japan show explosive roots related to the middle regime, so that variations in unemployment pass this regime rapidly in their way up or down, being stable for outstanding phases of business creation. In the rest of the countries the models are always stable.

Turning now to the causation running from unemployment to entrepreneurship, empirical evidence confirms again that business creation dynamics change with the state 
of variation in unemployment rates in the nine countries. This nonlinear behavior is described by the STAR-EXT models displayed in table 5. We confirm the asymmetric evolution looking at the p-values of the F linearity tests at a 0.10 significance level in table 6; linearity rejections are stronger for this direction of causality.

\section{INSERT TABLE 5 HERE}

\section{INSERT TABLE 6 HERE}

As well as unemployment, business creation has reasonably long univariate dynamics, however, contrary to what happened in the previous models, STAR-EXTs behave now as threshold specifications in the majority of the countries (see the mainly great values of gamma): business creation reacts rapidly to changes in unemployment variation, while we showed that the opposite response took longer time. This fact might be seen as an indicator of entrepreneurial initiative.

The evaluation of the fitted models proves to be acceptable. As in the opposite direction of causality, STAR-EXT models display an outstanding explanatory power: they can explain $24 \%$ to $67 \%$ of the residual variance of the best linear specification in all nine countries.

Once more, all the models are exponential except for one (see figure 2). Business creation responses to variations in unemployment are asymmetric, depending on whether unemployment is undergoing a great positive or negative increase (outer regime), or its values are within intermediate ones (middle regime); the valid model is a linear (different) one in each of both regimes. The logic behind the exponential transition has been remarked for business creation; in the current case, the existence of an "unemployment-entrepreneurship" cycle would make that a positive or negative intense growth in unemployment finally causes either less or more unemployment. 
The analysis of business creation local dynamics reveals the way it evolves over the phases of unemployment variation. By observing table 7 we appreciate explosive roots in the middle regime in seven of the eight exponential models: business creation passes quickly the stages of usual variation in unemployment towards the stable ones of an important decrease or increase in unemployment.

\section{INSERT TABLE 7 HERE}

The facts of having discovered high values for the slope parameter, as well as explosive roots in the middle regime of most exponential models, may be reflecting the dynamism of the labor market.

In conclusion, we have demonstrated that unemployment variation causes business creation (and vice versa) in a nonlinear way in all countries of our sample. Consequently, we are now able to explain why some countries did not show a linear causality either in one direction (France, Italy and Japan) or both directions (United Kingdom): our variables display asymmetric reactions to each other that can only be described in a nonlinear framework.

\section{Conclusions}

There are different ways to relate unemployment and entrepreneurship. The economic growth channel, for example, postulates that in modern economies entrepreneurship is one of the main engines of economic growth. In this sense, entrepreneurship by stimulating growth leads to a reduction in unemployment. Therefore there is a causality link that runs from entrepreneurship to unemployment, and the relation is negative. Alternative views, not necessarily opposed to the economic growth channel, may postulate different types of relation between unemployment and entrepreneurship. The Knight-Oxenfeldt view based on individual choices between unemployment, self- 
employment and employment, for example, favors the idea that causality runs from unemployment to entrepreneurship in a positive way, since unemployed individuals facing low prospects of wage employment, turn to self-employment as the best available choice. Another view based in the Gibrat's law, which sustains that firm growth is independent of size, implies that entrepreneurship may have little impact, if any, on unemployment. Recent literature goes one step further, claiming that the relation between unemployment and entrepreneurship is intrinsically dynamic, and possibly, nonlinear. According to this view, it is possible that they cause each other in a nonlinear way.

This paper follows the latter line of research and performs Granger-causality tests and STAR-EXT estimation to assess the causality direction and the nonlinear nature of the relation between unemployment and business creation for a set of OECD countries.

The Granger-causality tests show that there is bidirectional causality between unemployment variation and entrepreneurship for the countries that have the most flexible labor markets in our sample, i.e. Ireland, Germany, United States and Australia. Unemployment variation causes business creation in Italy and Japan, and for France, the causation runs from entrepreneurship to unemployment.

The empirical evidence from the STAR-EXT estimation reveals that unemployment variation causes business creation (and vice versa) in a nonlinear way in all countries of our sample. Business creation reacts rapidly to changes in unemployment variation, while the opposite response takes longer time. It is important to stress that the nonlinear models have higher explanatory power than the linear autoregression models. 
The results of the STAR-EXT estimation explain why some countries did not show a linear causality either in one direction (France, Italy and Japan) or both directions (United Kingdom): our variables display asymmetric reactions to each other that can only be described in a nonlinear framework.

\section{References}

Acs, Z.J. and D.B. Audretsch (1993) Conclusion, in Z.J. Acs and D.B. Audretsch (eds.), Small Firms and Entrepreneurship: An East-West Perspective, Cambridge University Press, Cambridge, UK.

Audretsch, D. B., M.A. Carree and A.R. Thurik (2001) Does entrepreneurship reduce unemployment?. Tinbergen Institute discussion paper TI01-074/3. Erasmus University Rotterdam.

Audretsch, D.B., and M. Fritsch (1994) The geography of firm births in Germany, Regional Studies 28, 359-365.

Audretsch, D.B. and A.R. Thurik (2000) Capitalism and democracy in the $21^{\text {st }}$ century: From the managed to the entrepreneurial economy, Journal of Evolutionary Economics $10,17-34$

Audretsch, D.B. and A.R. Thurik (2001) What's new about the new economy? From the managed to the entrepreneurial economy, Industrial and Corporate Change 10, 267-315. Audretsch, D.B. and A.R. Thurik (2004) The model of the entrepreneurial economy, International Journal of Entrepreneurial Education 2, 143-166.

Audretsch, D.B. and A.R. Thurik (2007) The models of the managed and the entrepreneurial economy, in H. Hanusch and A. Pyka (eds), The Elgar Companion to Neo-Schumpeterian Economics, Edward Elgar Publishing Limited, Cheltenham, UK and Northampton, MA, US, 211- 231. 
Box, G. E. P. and G. M. Jenkins (1970). Time series analysis, forecasting and control. San Francisco: Holden-Day.

Brock, W.A. and D.S. Evans (1989) Small business economics, Small Business Economics 1, 7-20.

Brown, C. and J. Medoff (1989) The employer size-wage effect, Journal of Political Economy 97, 1027-1059.

Cancelo, J.R. and E. Mourelle, (2005) Modeling cyclical asymmetries in European imports, International Advances in Economic Research 11 (2), 135-47.

Caves, R. (1982) Multinational Enterprise and Economic Analysis, Cambridge University Press, Cambridge, UK.

Carlsson, B. (1992) The rise of small business: Causes and consequences, in W.J. Adams (ed.), Singular Europe, Economy and Policy of the European Community After 1992, University of Michigan Press, Ann Arbor, pp. 145-169.

Chandler, A.D., Jr., (1990) Scale and Scope: The Dynamics of Industrial Capitalism, Harvard University Press, Cambridge, Mass.

Eitrheim, ø. and T. Teräsvirta (1996) Testing the adequacy of smooth transition autoregressive models, Journal of Econometrics 74, 59-75.

Evans, D. and L. Leighton (1990) Small business formation by unemployed and employed workers, Small Business Economics 2, 319-330.

Faria, J. R.; J. C. Cuestas and L. Gil-Alana (2008). Unemployment and entrepreneurship: a cyclical relation?. Discussion papers in Economics n. 2008/2, Nottingham Trent University.

Galbraith, J.K. (1956) American Capitalism: The Concept of Countervailing Power, Houghton Mifflin Co., Boston. 
Garofoli, G. (1994) New firm formation and regional development: The Italian case, Regional Studies 28, 381-394.

Geroski, P.A. (1995) What do we know about entry?, International Journal of Industrial Organization 13, 421-440.

Granger, C.W.J. and T. Teräsvirta (1993) Modelling Nonlinear Economic Relationships. Oxford: Oxford University Press.

Highfield, R. and R. Smiley (1987) New business starts and economic activity: An empirical investigation, International Journal of Industrial Organization 5, 51-66.

Knight, F.K. (1921) Risk, Uncertainty and Profit, Houghton Mifflin, New York.

$\mathrm{Ng}, \mathrm{S}$. and P. Perron (2001) Lag selection and the construction of unit root tests with good size and power, Econometrica 69, 1519-1554.

Öcal, N. and D.R. Osborn (2000) Business cycle non-linearities in UK consumption and production, Journal of Applied Econometrics 15, 27-43.

Oxenfeldt, A. (1943) New Firms and Free Enterprise, Washington, D.C., American Council on Public Affairs.

Prachowny, M.F.J. (1993) Okun's Law: Theoretical foundations and revised estimates, Review of Economics and Statistics 75, 331-336.

Pratten, C.F. (1971) Economies of Scale in Manufacturing Industry, Cambridge University Press, Cambridge, UK.

Scherer, F.M. (1991) Changing perspectives on the firm size problem, in Z.J. Acs and D.B. Audretsch (eds.) Innovation and Technological Change: An International Comparison, University of Michigan Press, Ann Arbor, pp. 24-38.

Schumpeter, J.A. ([1908], 1934) The Theory of Economic Development, Harvard Univ. Press, Cambridge, Mass. 
Schumpeter, J.A. (1942) Capitalism, Socialism and Democracy, Harper and Row, New York.

Sensier, M.; N. Öcal and D. R. Osborn (2002) Asymmetric interest rate effects for the UK real economy, Oxford Bulletin of Economics and Statistics 64 (4), 315-39.

Sutton, J. (1997) Gibrat's legacy, Journal of Economic Literature 35, 40-59.

Teräsvirta, T. (1994) Specification, estimation, and evaluation of smooth transition autoregressive models, Journal of the American Statistical Association 89 (425), 20818.

Teräsvirta, T. (1998) Modeling economic relationships with smooth transition regressions, in A. Ullah and D.E.A. Giles (eds.) Handbook of Applied Economic Statistics, New York: Marcel Dekker, pp. 507-52.

Thurik, R. (2008) Entreprenomics: Entrepreneurship, economic growth and policy, in Z.J. Acs, D.B. Audretsch and R. Strom (eds.) Entrepreneurship, Growth and Public Policy, Cambridge University Press, Cambridge, UK, forthcoming.

van Dijk, D.; T. Teräsvirta and P.H. Franses (2002) Smooth transition autoregressive models - A survey of recent developments, Econometric Reviews 21 (1), 1-47. 
TABLE 1

Granger causality test

\begin{tabular}{|c|c|c|c|}
\hline Country & $H_{0}$ & $i$ & p-value \\
\hline \multirow[t]{2}{*}{ Ireland } & $\Delta^{i} u_{t} \nrightarrow \Delta^{i} e_{t}$ & 3 & 0.09 \\
\hline & $\Delta^{i} e_{t} \nrightarrow \Delta^{i} u_{t}$ & 3 & 0.02 \\
\hline \multirow[t]{2}{*}{ France } & $\Delta^{i} u_{t} \nrightarrow \Delta^{i} e_{t}$ & 4 & 0.64 \\
\hline & $\Delta^{i} e_{t} \nrightarrow \Delta^{i} u_{t}$ & 4 & 0.06 \\
\hline \multirow[t]{2}{*}{ Italy } & $\Delta^{i} u_{t} \rightarrow \Delta^{i} e_{t}$ & 4 & 0.07 \\
\hline & $\Delta^{i} e_{t} \nrightarrow \Delta^{i} u_{t}$ & 4 & 0.50 \\
\hline \multirow[t]{2}{*}{ Germany } & $\Delta^{i} e_{t} \rightarrow \Delta^{i} u_{t}$ & 2 & 0.01 \\
\hline & $\Delta^{i} u_{t} \nrightarrow \Delta^{i} e_{t}$ & 3 & 0.04 \\
\hline \multirow[t]{2}{*}{ Spain } & $\Delta^{i} u_{t} \nrightarrow \Delta^{i} e_{t}$ & 2 & 0.11 \\
\hline & $\Delta^{i} e_{t} \nrightarrow \Delta^{i} u_{t}$ & 2 & 0.02 \\
\hline \multirow[t]{2}{*}{ United States } & $\Delta^{i} u_{t} \nrightarrow \Delta^{i} e_{t}$ & 2 & 0.01 \\
\hline & $\Delta^{i} e_{t} \rightarrow \Delta^{i} u_{t}$ & 2 & 0.07 \\
\hline \multirow[t]{2}{*}{ Japan } & $\Delta^{i} u_{t} \nrightarrow \Delta^{i} e_{t}$ & 3 & 0.08 \\
\hline & $\Delta^{i} e_{t} \rightarrow \Delta^{i} u_{t}$ & 3 & 0.56 \\
\hline \multirow[t]{2}{*}{ Australia } & $\Delta^{i} u_{t} \rightarrow \Delta^{i} e_{t}$ & 2 & 0.00 \\
\hline & $\Delta^{i} e_{t} \rightarrow \Delta^{i} u_{t}$ & 2 & 0.07 \\
\hline
\end{tabular}




\section{TABLE 2}

\section{Estimated STAR-EXT models for variation in unemployment}

\section{AUSTRALIA}

$$
\begin{aligned}
\Delta u_{t}= & \underset{(0.41)}{0.56}+\underset{(0.65)}{1.80} \Delta u_{t-1}-\underset{(0.46)}{1.18} \Delta u_{t-2} \\
& +(-\underset{(0.56)}{0.95}-\underbrace{1.80}_{(0.65)} \Delta u_{t-1}+\underset{(0.59)}{0.81} \Delta u_{t-2}+\underset{(0.35)}{0.52} \Delta u_{t-3}+\underset{(0.24)}{0.04} \Delta u_{t-5}) \\
& \times\left[1-\exp \left\{-\underset{(0.81)}{1.22} \times 42967.89\left(\Delta e_{t-4}+\underset{(0.0005)}{0.0002}\right)^{2}\right\}\right]+a_{t}
\end{aligned}
$$

$\mathrm{s}=0.6396, \bar{R}^{2}=0.44, \mathrm{~s}^{2} / \mathrm{s}_{\mathrm{L}}^{2}=0.56, \mathrm{ARCH}=0.99(0.44), \mathrm{BCH}=0.07(0.79), \mathrm{AUTO}=0.78(0.56)$, $\mathrm{NL}=8.81(0.26), \mathrm{PC}=1.44(0.43)$

\section{FRANCE}

$$
\begin{aligned}
\Delta u_{t}= & \underset{(0.23)}{0.55}-\underset{(0.42)}{0.15} \Delta u_{t-1}+\underset{(0.44)}{0.81} \Delta u_{t-2}+\underset{(0.59)}{1.38} \Delta u_{t-3}-\underset{(0.74)}{2.64} \Delta u_{t-4} \\
& +\left(-\underset{(0.38)}{0.24}+\underset{(0.58)}{0.84} \Delta u_{t-1}-\underset{(0.61)}{1.25} \Delta u_{t-2}-\underset{(0.74)}{1.74} \Delta u_{t-3}+\underset{(0.80)}{3.00} \Delta u_{t-4}\right) \\
& \times\left[1-\exp \left\{-\underset{(1.34)}{2.84} \times 444643.64\left(\Delta e_{t-1}+\underset{(0.0001)}{0.0019}\right)^{2}\right\}\right]+a_{t}
\end{aligned}
$$

$\mathrm{s}=0.4291, \bar{R}^{2}=0.43, \mathrm{~s}^{2} / \mathrm{s}_{\mathrm{L}}^{2}=0.48, \mathrm{ARCH}=0.51(0.73), \mathrm{BCH}=0.25(0.62), \mathrm{AUTO}=2.54(0.12)$, $\mathrm{NL}=1.80(0.21), \mathrm{PC}=2.38(0.15)$

\section{GERMANY}

$$
\begin{aligned}
\Delta u_{t}= & -\underset{(0.22)}{0.27}+\underset{(0.25)}{1.09} \Delta u_{t-1}-\underset{(0.16)}{0.51} \Delta u_{t-2}+\left(\underset{(0.41)}{1.199}-\underset{(0.25)}{1.09} \Delta u_{t-1}\right) \\
& \times\left[1-\exp \left\{-\underset{(0.45)}{0.83} \times 263829.76\left(\Delta e_{t-1}+\underset{(0.0003)}{0.0003}\right)^{2}\right\}\right]+a_{t}
\end{aligned}
$$

$\mathrm{s}=0.5490, \bar{R}^{2}=0.46, \mathrm{~s}^{2} / \mathrm{s}_{\mathrm{L}}^{2}=0.86, \mathrm{ARCH}=1.17(0.35), \mathrm{BCH}=0.01(0.92), \mathrm{AUTO}=1.27(0.32)$, $\mathrm{NL}=1.86(0.14), \mathrm{PC}=0.40(0.87)$

\section{IRELAND}

$$
\begin{aligned}
& \Delta u_{t}=\underset{(0.72)}{0.29}-\underset{(0.68)}{0.98} \Delta u_{t-1}-\underset{(0.53)}{0.80} \Delta u_{t-3}+\underset{(0.46)}{0.43} \Delta u_{t-4} \\
& +\left(-\underset{(0.80)}{0.51}+\underset{(0.68)}{1.75} \Delta u_{t-1}+\underset{(0.53)}{0.80} \Delta u_{t-3}-\underset{(0.51)}{0.62} \Delta u_{t-4}\right)
\end{aligned}
$$

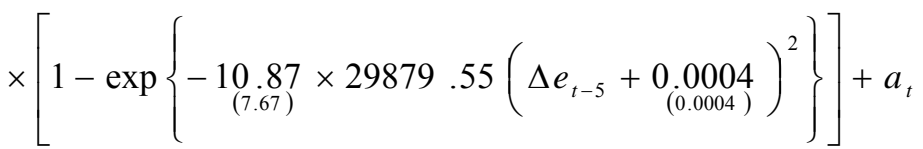

$\mathrm{s}=0.8056, \bar{R}^{2}=0.47, \mathrm{~s}^{2} / \mathrm{s}_{\mathrm{L}}^{2}=0.58, \mathrm{ARCH}=0.38(0.82), \mathrm{BCH}=1.75(0.20), \mathrm{AUTO}=0.80(0.55)$, $\mathrm{NL}=5.03(0.04), \mathrm{PC}=2.14(0.20)$ 


\section{ITALY}

$$
\begin{aligned}
& \Delta u_{t}=-\underset{(0.17)}{0.31}+\underset{(0.34)}{1.10} \Delta u_{t-1}-\underset{(0.42)}{0.60} \Delta u_{t-2}+\underset{(0.26)}{0.41} \Delta u_{t-3} \\
& +\left(\underset{(0.26)}{0.65}-\underset{(0.34)}{1.10} \Delta u_{t-1}+\underset{(0.63)}{1.05} \Delta u_{t-2}-\underset{(0.26)}{0.41} \Delta u_{t-3}\right) \\
& \times\left[1-\exp \left\{\underset{(0.65)}{-0.79} \times 105274.33\left(\Delta e_{t-3}+\underset{(0.0009)}{0.0031}\right)^{2}\right\}\right]+a_{t}
\end{aligned}
$$

$\mathrm{s}=0.3489, \bar{R}^{2}=0.43, \mathrm{~s}^{2} / \mathrm{s}_{\mathrm{L}}^{2}=0.70, \mathrm{ARCH}=1.12(0.37), \mathrm{BCH}=0.70(0.41), \mathrm{AUTO}=1.20(0.36)$, $\mathrm{NL}=1.41(0.29), \mathrm{PC}=0.99(0.48)$

\section{JAPAN}

$$
\begin{aligned}
& \Delta u_{t}=-\underset{(0.15)}{0.22}+\underset{(0.34)}{0.42} \Delta u_{t-1}+\underset{(0.40)}{0.48} \Delta u_{t-2}+\underset{(0.65)}{1.86} \Delta u_{t-5} \\
& +\left(\underset{(0.17)}{0.41-\underset{(0.34)}{0.42} \Delta u_{t-1}}-\underset{(0.40)}{0.48} \Delta u_{t-2}-\underset{(0.68)}{2.72} \Delta u_{t-5}\right) \\
& \times\left[1-\exp \left\{-\underset{(1.25)}{2.86} \times 292539.05\left(\Delta e_{t-3}+\underset{(0.0002)}{0.0025}\right)^{2}\right\}\right]+a_{t}
\end{aligned}
$$

$\mathrm{s}=0.1803, \bar{R}^{2}=0.46, \mathrm{~s}^{2} / \mathrm{s}_{\mathrm{L}}^{2}=0.66, \mathrm{ARCH}=1.24(0.33), \mathrm{BCH}=0.004(0.95), \mathrm{AUTO}=0.44(0.78)$, $\mathrm{NL}=2.83(0.10), \mathrm{PC}=1.85(0.21)$

\section{SPAIN}

$$
\begin{aligned}
\Delta u_{t}= & -\underset{(0.32)}{0.61}+\underset{(0.17)}{0.88} \Delta u_{t-1}-\underset{(0.28)}{0.49} \Delta u_{t-2} \\
& \left.+\underset{(0.48)}{(1.24}+\underset{(0.28)}{0.49} \Delta u_{t-2}-\underset{(0.17)}{0.23} \Delta u_{t-4}\right) \\
& \times\left[1-\exp \left\{-\underset{(i .11)}{1.13} \times 102320.79\left(\Delta e_{t-3}-\underset{(0.0009)}{0.0005}\right)^{2}\right\}\right]+a_{t}
\end{aligned}
$$

$\mathrm{s}=0.6911, \bar{R}^{2}=0.67, \mathrm{~s}^{2} / \mathrm{s}_{\mathrm{L}}^{2}=0.69, \mathrm{ARCH}=0.17(0.95), \mathrm{BCH}=0.21 \quad(0.65), \mathrm{AUTO}=2.11(0.14)$, $\mathrm{NL}=2.17(0.17), \mathrm{PC}=0.99(0.50)$

\section{UNITED KINGDOM}

$$
\begin{aligned}
\Delta u_{t}= & \underset{(0.41)}{0.71}+\underset{(0.11)}{0.48} \Delta u_{t-1}-\underset{(0.30)}{0.66} \Delta u_{t-3} \\
& +\left(-\underset{(0.50)}{0.90}+\underset{(0.11)}{0.48} \Delta u_{t-1}-\underset{(0.35)}{0.73} \Delta u_{t-2}+\underset{(0.44)}{1.11} \Delta u_{t-3}\right) \\
& \times\left[1-\exp \left\{-\underset{(2.84)}{2.88} \times 78140.99\left(\Delta e_{t-3}-\underset{(0.0006)}{0.0002}\right)^{2}\right\}\right]+a_{t}
\end{aligned}
$$

$\mathrm{s}=0.7415, \bar{R}^{2}=0.46, \mathrm{~s}^{2} / \mathrm{s}_{\mathrm{L}}^{2}=0.74, \mathrm{ARCH}=0.37(0.83), \mathrm{BCH}=2.52(0.12), \mathrm{AUTO}=0.63(0.65)$, $\mathrm{NL}=29.26(0.14), \mathrm{PC}=0.83(0.63)$ 


\section{UNITED STATES}

$$
\begin{aligned}
\Delta u_{t}= & 1_{(1.51)}^{1.79}+\underset{(0.85)}{1.59} \Delta u_{t-1}+\underset{(1.07)}{1.30} \Delta u_{t-2}+\underset{(0.69)}{0.80} \Delta u_{t-4} \\
& +\left(-\underset{(1.50)}{2.08}-1_{(0.85)}^{1.59} \Delta u_{t-1}-\underset{(1.07)}{1.68} \Delta u_{t-2}-\underset{(0.69)}{1.60} \Delta u_{t-4}+\underset{(0.12)}{0.01} \Delta u_{t-5}\right) \\
& \times\left[1-\exp \left\{-\underset{(5.79)}{7.19} \times 240368.32\left(\Delta e_{t}-\underset{(0.0002)}{0.0004}\right)^{2}\right\}\right]+a_{t}
\end{aligned}
$$

$\mathrm{s}=0.4156, \bar{R}^{2}=0.62, \mathrm{~s}^{2} / \mathrm{s}_{\mathrm{L}}^{2}=0.39, \mathrm{ARCH}=0.76(0.56), \mathrm{BCH}=4.34(0.05), \mathrm{AUTO}=4.31(0.03)$, $\mathrm{NL}=5.17(0.05), \mathrm{PC}=0.72(0.70)$

Notes: $\Delta \mathrm{u}_{\mathrm{t}}\left(\Delta \mathrm{e}_{\mathrm{t}}\right)$ denotes variation in unemployment (business creation). Values under regression coefficients are standard errors of the estimates; $\mathrm{s}$ is the residual standard error; $\bar{R}^{2}$ the adjusted determination coefficient; $\mathrm{s}^{2} / \mathrm{s}^{2}{ }_{\mathrm{L}}$ is the variance ratio of the residuals from the nonlinear model and the best linear AR selected with AIC; ARCH is the statistic of no ARCH based on four lags; $\mathrm{BCH}$ is a business cycle heteroskedasticity test; AUTO is the test for residual autocorrelation of order 4; $\mathrm{NL}$ is the test for no remaining nonlinearity; PC is the parameter constancy test. Numbers in parentheses after values of $\mathrm{ARCH}, \mathrm{BCH}$, AUTO, NL and PC are p-values. 
TABLE 3

Linearity tests against STAR-EXT models for variation in unemployment: p-values

Country (lag order)

\begin{tabular}{ll}
\hline \hline Australia $(p=6)$ & 0.0106 \\
France $(p=4)$ & 0.0630 \\
Germany $(p=2)$ & 0.0374 \\
Ireland $(p=5)$ & 0.0141 \\
Italy $(p=3)$ & 0.0965 \\
Japan $(p=5)$ & 0.0099 \\
Spain $(p=4)$ & 0.0072 \\
United Kingdom $(p=5)$ & 0.1072 \\
United States $(p=5)$ & 0.0007 \\
\hline
\end{tabular}




\section{TABLE 4}

Local dynamics of the models for variation in unemployment: dominant roots in each regime

\begin{tabular}{lccc}
\hline Country & Regime (value of F) & Root & Modulus \\
\hline Australia & Middle $(\mathrm{F}=0)$ & $0.8987 \pm 0.6109 \mathrm{i}$ & 1.09 \\
& Outer $(\mathrm{F}=1)$ & $-0.3270 \pm 0.8063 \mathrm{i}$ & 0.87 \\
\hline France & Middle $(\mathrm{F}=0)$ & $-1.0588 \pm 0.9760 \mathrm{i}$ & 1.44 \\
& Outer $(\mathrm{F}=1)$ & $0.3763 \pm 0.8628 \mathrm{i}$ & 0.94 \\
\hline Germany & Middle $(\mathrm{F}=0)$ & $0.5433 \pm 0.4659 \mathrm{i}$ & 0.72 \\
& Outer $(\mathrm{F}=1)$ & $0 \pm 0.7157 \mathrm{i}$ & 0.72 \\
\hline Ireland & Middle $(\mathrm{F}=0)$ & -1.4798 & 1.48 \\
& Outer $(\mathrm{F}=1)$ & $0.7157 \pm 0.3713 \mathrm{i}$ & 0.81 \\
\hline Italy & Middle $(\mathrm{F}=0)$ & 0.9289 & 0.93 \\
\hline Japan & Outer $(\mathrm{F}=1)$ & 0.6701 & 0.67 \\
\hline Spain & Middle $(\mathrm{F}=0)$ & 1.3458 & 1.35 \\
& Outer $(\mathrm{F}=1)$ & -0.9694 & 0.97 \\
\hline United Kingdom & Middle $(\mathrm{F}=0)$ & $0.4385 \pm 0.5501 \mathrm{i}$ & 0.70 \\
\hline United States & Outer $(\mathrm{F}=1)$ & $0.7771 \pm 0.3594 \mathrm{i}$ & 0.86 \\
\hline & Oiddle $(\mathrm{F}=0)$ & $0.6101 \pm 0.7250 \mathrm{i}$ & 0.95 \\
& Outer $(\mathrm{F}=1)$ & 0.7765 & 0.78 \\
\hline
\end{tabular}


TABLE 5

Estimated STAR-EXT models for business creation

\section{AUSTRALIA}

$$
\begin{aligned}
\Delta e_{t}= & -\underset{(0.002)}{0.003}-\underset{(0.36)}{0.59} \Delta e_{t-1} \\
& +\left(\underset{(0.002)}{0.007}+\underset{(0.36)}{0.59} \Delta e_{t-1}+\underset{(0.28)}{0.54} \Delta e_{t-4}\right) \\
& \times\left[1+\exp \left\{-\underset{(2.69)}{3.78} \times 0.96\left(\Delta u_{t-2}-\underset{(0.2997)}{0.3577}\right)\right\}\right]^{-1}+a_{t}
\end{aligned}
$$

$\mathrm{s}=0.0032, \bar{R}^{2}=0.35, \mathrm{~s}^{2} / \mathrm{s}_{\mathrm{L}}^{2}=0.63, \mathrm{ARCH}=0.92(0.47), \mathrm{BCH}=0.20(0.65), \mathrm{AUTO}=0.76(0.57)$, $\mathrm{NL}=5.96(0.01), \mathrm{PC}=0.86(0.58)$

\section{FRANCE}

$$
\begin{aligned}
\Delta e_{t}= & \underset{(0.0022)}{0.0007}+\underset{(0.11)}{0.22} \Delta e_{t-1}+\underset{(0.86)}{1.52} \Delta e_{t-2}-\underset{(0.18)}{0.27} \Delta e_{t-4} \\
& +\left(-0.0022+\underset{(0.0023)}{0.22} \Delta e_{t-1}-\underset{(0.86)}{1.52} \Delta e_{t-2}\right) \\
& \times\left[1-\exp \left\{-\underset{(2.04)}{2.98} \times 1.94\left(\Delta u_{t-2}-\underset{(0.0889)}{0.7889}\right)^{2}\right\}\right]+a_{t}
\end{aligned}
$$

$\mathrm{s}=0.0009, \bar{R}^{2}=0.32, \mathrm{~s}^{2} / \mathrm{s}_{\mathrm{L}}^{2}=0.76, \mathrm{ARCH}=0.81(0.53), \mathrm{BCH}=0.26(0.61), \mathrm{AUTO}=3.22(0.05)$, $\mathrm{NL}=2.32(0.12), \mathrm{PC}=1.93(0.15)$

\section{GERMANY}

$$
\begin{aligned}
\Delta e_{t}= & -\underset{(0014)}{0.0022}+\underset{(0.63)}{1.07} \Delta e_{t-1}+\underset{(1.21)}{2.64} \Delta e_{t-4}-\underset{(1.80)}{3.43} \Delta e_{t-5} \\
& +\left(\underset{(0.0014)}{0.0030}-\underset{(0.63)}{1.07} \Delta e_{t-1}+\underset{(0.15)}{0.31} \Delta e_{t-3}-\underset{(i .21)}{2.64} \Delta e_{t-4}+\underset{(i .80)}{3.43} \Delta e_{t-5}\right) \\
& \times\left[1-\exp \left\{-\underset{(7.78)}{13.89} \times 1.53\left(\Delta u_{t-3}+\underset{(0.0435)}{0.0083}\right)^{2}\right\}\right]+a_{t}
\end{aligned}
$$

$\mathrm{s}=0.0009, \bar{R}^{2}=0.57, \mathrm{~s}^{2} / \mathrm{s}_{\mathrm{L}}^{2}=0.49, \mathrm{ARCH}=0.64(0.64), \mathrm{BCH}=3.68(0.07), \mathrm{AUTO}=0.55(0.70)$, $\mathrm{NL}=99.82(0.08), \mathrm{PC}=0.58(0.80)$

\section{IRELAND}

$$
\begin{aligned}
\Delta e_{t}= & 0_{(0.0034)}^{0.0064}+1_{(0.72)}^{14} \Delta e_{t-4} \\
& +\left(-0_{(0.0037)}^{0.0114}-\underset{(0.20)}{0.35} \Delta e_{t-1}+\underset{(0.24)}{0.68} \Delta e_{t-2}-\underset{(0.77)}{1.64} \Delta e_{t-4}\right) \\
& \times\left[1-\exp \left\{-\underset{(3.63)}{5.46} \times 0.46\left(\Delta u_{t-1}+\underset{(0.1428)}{0.1111}\right)^{2}\right\}\right]+a_{t}
\end{aligned}
$$

$\mathrm{s}=0.0043, \bar{R}^{2}=0.34, \mathrm{~s}^{2} / \mathrm{s}_{\mathrm{L}}^{2}=0.60, \mathrm{ARCH}=0.57(0.69), \mathrm{BCH}=2.26(0.14), \mathrm{AUTO}=1.31 \quad(0.32)$, $\mathrm{NL}=10.24(0.04), \mathrm{PC}=0.79(0.64)$ 


\section{ITALY}

$$
\begin{aligned}
\Delta e_{t}= & -\underset{(0.0016)}{0.0031}-\underset{(0.61)}{0.54} \Delta e_{t-1}-\underset{(0.71)}{1.87} \Delta e_{t-2}-\underset{(1.13)}{2.82} \Delta e_{t-3} \\
& +\left(\underset{(0.0018)}{0.0030}+\underset{(0.68)}{0.65} \Delta e_{t-1}+\underset{(0.71)}{1.87} \Delta e_{t-2}+\underset{(1.15)}{3.25} \Delta e_{t-3}\right) \\
& \times\left[1-\exp \left\{-\underset{(0.65)}{1.19} \times 3.37\left(\Delta u_{t}+\underset{(0.1072)}{0.5643}\right)^{2}\right\}\right]+a_{t}
\end{aligned}
$$

$\mathrm{s}=0.0021, \bar{R}^{2}=0.27, \mathrm{~s}^{2} / \mathrm{s}_{\mathrm{L}}^{2}=0.75, \mathrm{ARCH}=1.05(0.40), \mathrm{BCH}=0.89(0.35), \mathrm{AUTO}=1.09(0.40)$, $\mathrm{NL}=2.55(0.09), \mathrm{PC}=0.46(0.86)$

\section{JAPAN}

$$
\begin{aligned}
\Delta e_{t}= & \underset{(0.0023)}{0.0028}+\underset{(0.40)}{0.98} \Delta e_{t-2}+\underset{(0.44)}{0.58} \Delta e_{t-4} \\
& +\left(-\underset{(0.0024)}{0.0065}+\underset{(0.28)}{0.52} \Delta e_{t-1}-\underset{(0.46)}{1.44} \Delta e_{t-2}-\underset{(0.27)}{0.36} \Delta e_{t-3}-\underset{(0.44)}{0.58} \Delta e_{t-4}\right) \\
& \times\left[1-\exp \left\{-\underset{(2.16)}{3.22} \times 13.08\left(\Delta u_{t-2}+\underset{(0.0305)}{0.0735}\right)^{2}\right\}\right]+a_{t}
\end{aligned}
$$

$\mathrm{s}=0.0013, \bar{R}^{2}=0.26, \mathrm{~s}^{2} / \mathrm{s}_{\mathrm{L}}^{2}=0.80, \mathrm{ARCH}=1.88(0.15), \mathrm{BCH}=2.86(0.10), \mathrm{AUTO}=0.82(0.54)$, $\mathrm{NL}=1.90(0.25), \mathrm{PC}=0.39(0.92)$

\section{SPAIN}

$$
\begin{aligned}
& \Delta e_{t}=\underset{(0.0031)}{0.0059}+\underset{(0.69)}{1.04} \Delta e_{t-1}-\underset{(0.14)}{0.24} \Delta e_{t-2}+\underset{(0.57)}{1.64} \Delta e_{t-4} \\
& +\left(-\underset{(0.0032)}{0.0095}-1.58 \Delta e_{t-1}-1.64 \Delta e_{t-4}\right) \\
& \times\left[1-\exp \left\{-\underset{(1.57)}{3.53} \times 0.55\left(\Delta u_{t-4}-\underset{(0.1529)}{0.9861}\right)^{2}\right\}\right]+a_{t}
\end{aligned}
$$

$\mathrm{s}=0.0016, \bar{R}^{2}=0.45, \mathrm{~s}^{2} / \mathrm{s}_{\mathrm{L}}^{2}=0.53, \mathrm{ARCH}=1.44(0.26), \mathrm{BCH}=0.11(0.74), \mathrm{AUTO}=0.86(0.51)$, $\mathrm{NL}=2.53(0.32), \mathrm{PC}=2.16(0.16)$

\section{UNITED KINGDOM}

$$
\begin{aligned}
\Delta e_{t}= & 0.0049+\underset{(0.0012)}{1.37} \Delta e_{t-2}-\underset{(0.14)}{0.18} \Delta e_{t-3} \\
& +(-\underset{(0.0054)}{0.0054}+\underset{(0.16)}{0.50} \Delta e_{t-1}-\underbrace{1.37}_{(0.43)} \Delta e_{t-2}-\underset{(0.13)}{0.37} \Delta e_{t-4}) \\
& \times\left[1-\exp \left\{-\underset{(6.48)}{10.22} \times 0.77\left(\Delta u_{t}+\underset{(0.0576)}{0.1543}\right)^{2}\right\}\right]+a_{t}
\end{aligned}
$$

$\mathrm{s}=0.0018, \bar{R}^{2}=0.66, \mathrm{~s}^{2} / \mathrm{s}_{\mathrm{L}}^{2}=0.33, \mathrm{ARCH}=0.48(0.75), \mathrm{BCH}=4.40(0.04), \mathrm{AUTO}=0.24(0.91)$, $\mathrm{NL}=2.10(0.18), \mathrm{PC}=0.27(0.97)$ 


\section{UNITED STATES}

$$
\begin{aligned}
\Delta e_{t}= & -\underset{(0.0006)}{0.0009}+\underset{(0.38)}{1.09} \Delta e_{t-1}-\underset{(0.47)}{0.82} \Delta e_{t-2}+\underset{(0.26)}{0.28} \Delta e_{t-3} \\
& +\left(\underset{(0.0009)}{0.0023}-\underset{(0.38)}{1.09} \Delta e_{t-1}+\underset{(0.67)}{1.58} \Delta e_{t-2}-\underset{(0.26)}{0.28} \Delta e_{t-3}-\underset{(0.52)}{0.66} \Delta e_{t-4}\right) \\
& \times\left[1-\exp \left\{\underset{(1.49)}{-1.69} \times 1.10\left(\Delta u_{t}+\underset{(0.1380)}{0.2611}\right)^{2}\right\}\right]+a_{t}
\end{aligned}
$$

$\mathrm{s}=0.0014, \bar{R}^{2}=0.37, \mathrm{~s}^{2} / \mathrm{s}_{\mathrm{L}}^{2}=0.59, \mathrm{ARCH}=0.26(0.90), \mathrm{BCH}=0.11(0.74), \mathrm{AUTO}=1.65(0.23)$, $\mathrm{NL}=2.11(0.18), \mathrm{PC}=7.83(0.002)$

Notes: $\Delta \mathrm{u}_{\mathrm{t}}\left(\Delta \mathrm{e}_{\mathrm{t}}\right)$ denotes variation in unemployment (business creation). Values under regression coefficients are standard errors of the estimates; $\mathrm{s}$ is the residual standard error; $\bar{R}^{2}$ the adjusted determination coefficient; $\mathrm{s}^{2} / \mathrm{s}_{\mathrm{L}}^{2}$ is the variance ratio of the residuals from the nonlinear model and the best linear AR selected with AIC; ARCH is the statistic of no ARCH based on four lags; $\mathrm{BCH}$ is a business cycle heteroskedasticity test; AUTO is the test for residual autocorrelation of order 4; $\mathrm{NL}$ is the test for no remaining nonlinearity; PC is the parameter constancy test. Numbers in parentheses after values of $\mathrm{ARCH}, \mathrm{BCH}$, AUTO, NL and PC are p-values. 
TABLE 6

Linearity tests against STAR-EXT models for business creation: p-values

Country (lag order)

\begin{tabular}{ll}
\hline \hline Australia $(p=4)$ & 0.0004 \\
France $(p=4)$ & 0.0263 \\
Germany $(p=5)$ & 0.0011 \\
Ireland $(p=4)$ & 0.0093 \\
Italy $(p=3)$ & 0.0281 \\
Japan $(p=4)$ & 0.0479 \\
Spain $(p=5)$ & 0.0037 \\
United Kingdom $(p=4)$ & 0.0000 \\
United States $(p=4)$ & 0.0152 \\
\hline
\end{tabular}


TABLE 7

Local dynamics of the models for business creation: dominant roots in each regime

\begin{tabular}{lccc}
\hline Country & Regime (value of F) & Root & Modulus \\
\hline Australia & Lower $(\mathrm{F}=0)$ & -0.5893 & 0.59 \\
& Upper $(\mathrm{F}=1)$ & -0.8564 & 0.86 \\
\hline France & Middle $(\mathrm{F}=0)$ & 1.2767 & 1.28 \\
& Outer $(\mathrm{F}=1)$ & $0.6376 \pm 0.4891 \mathrm{i}$ & 0.80 \\
\hline Germany & Middle $(\mathrm{F}=0)$ & -1.3038 & 1.30 \\
\hline Ireland & Outer $(\mathrm{F}=1)$ & $-0.3400 \pm 0.5889 \mathrm{i}$ & 0.68 \\
& Middle $(\mathrm{F}=0)$ & -1.0326 & 1.03 \\
\hline Italy & Outer $(\mathrm{F}=1)$ & $-0.8195 \pm 0.3577 \mathrm{i}$ & 0.89 \\
\hline Japan & Middle $(\mathrm{F}=0)$ & $0.2886 \pm 1.5598 \mathrm{i}$ & 1.59 \\
& Outer $(\mathrm{F}=1)$ & 0.7929 & 0.79 \\
\hline Spain & Middle $(\mathrm{F}=0)$ & 1.1825 & 1.18 \\
& Outer $(\mathrm{F}=1)$ & $0.4692 \pm 0.7962 \mathrm{i}$ & 0.92 \\
\hline United Kingdom & Middle $(\mathrm{F}=0)$ & 1.4340 & 1.43 \\
\hline United States & Outer $(\mathrm{F}=1)$ & $-0.2698 \pm 0.4102 \mathrm{i}$ & 0.49 \\
\hline & Oiddle $(\mathrm{F}=0)$ & -1.2321 & 1.23 \\
& Outer $(\mathrm{F}=1)$ & $0.7080 \pm 0.6024 \mathrm{i}$ & 0.93 \\
\hline
\end{tabular}


FIGURE 1

Estimated transition functions for variation in employment
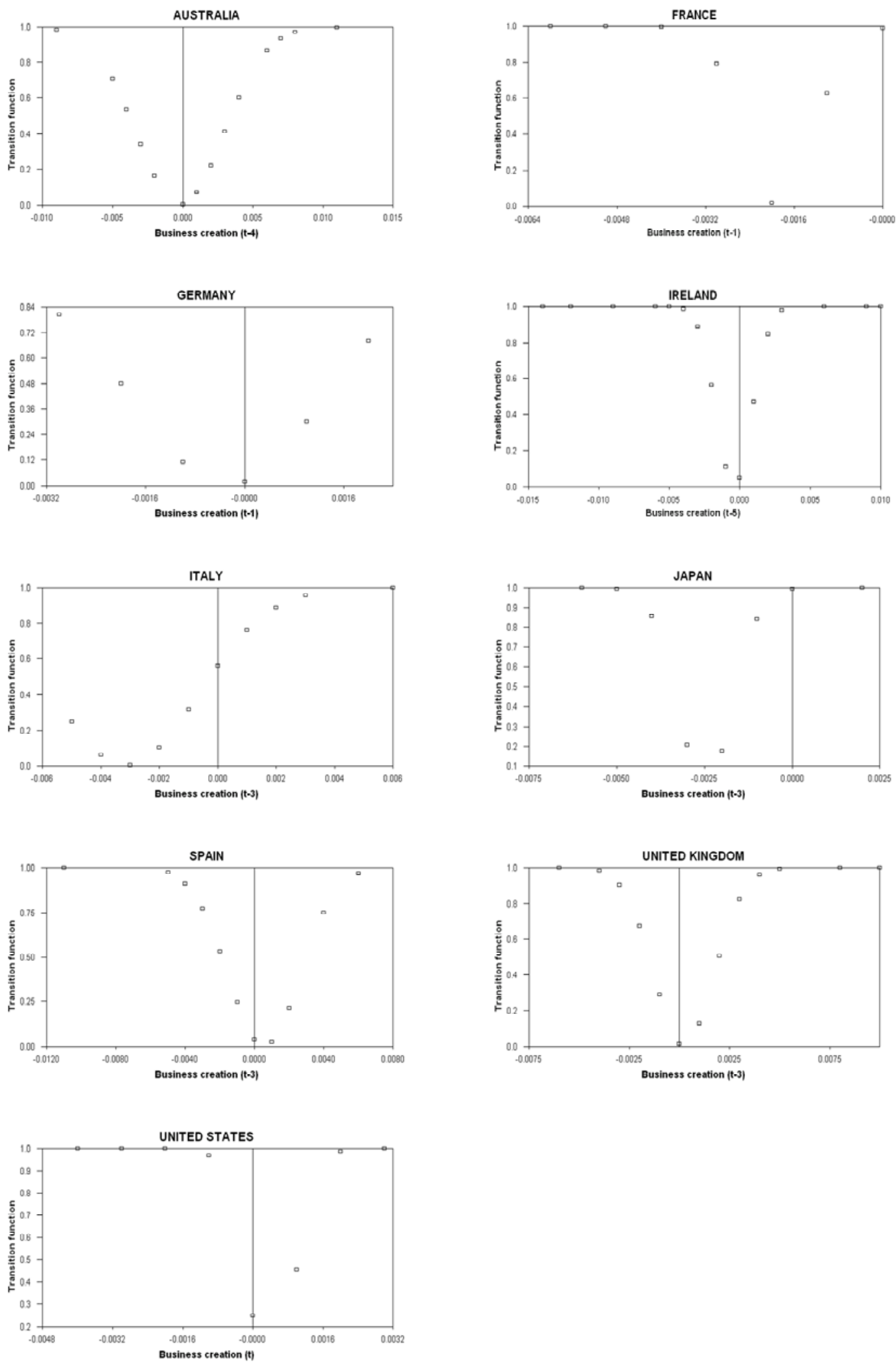
FIGURE 2

Estimated transition functions for business creation
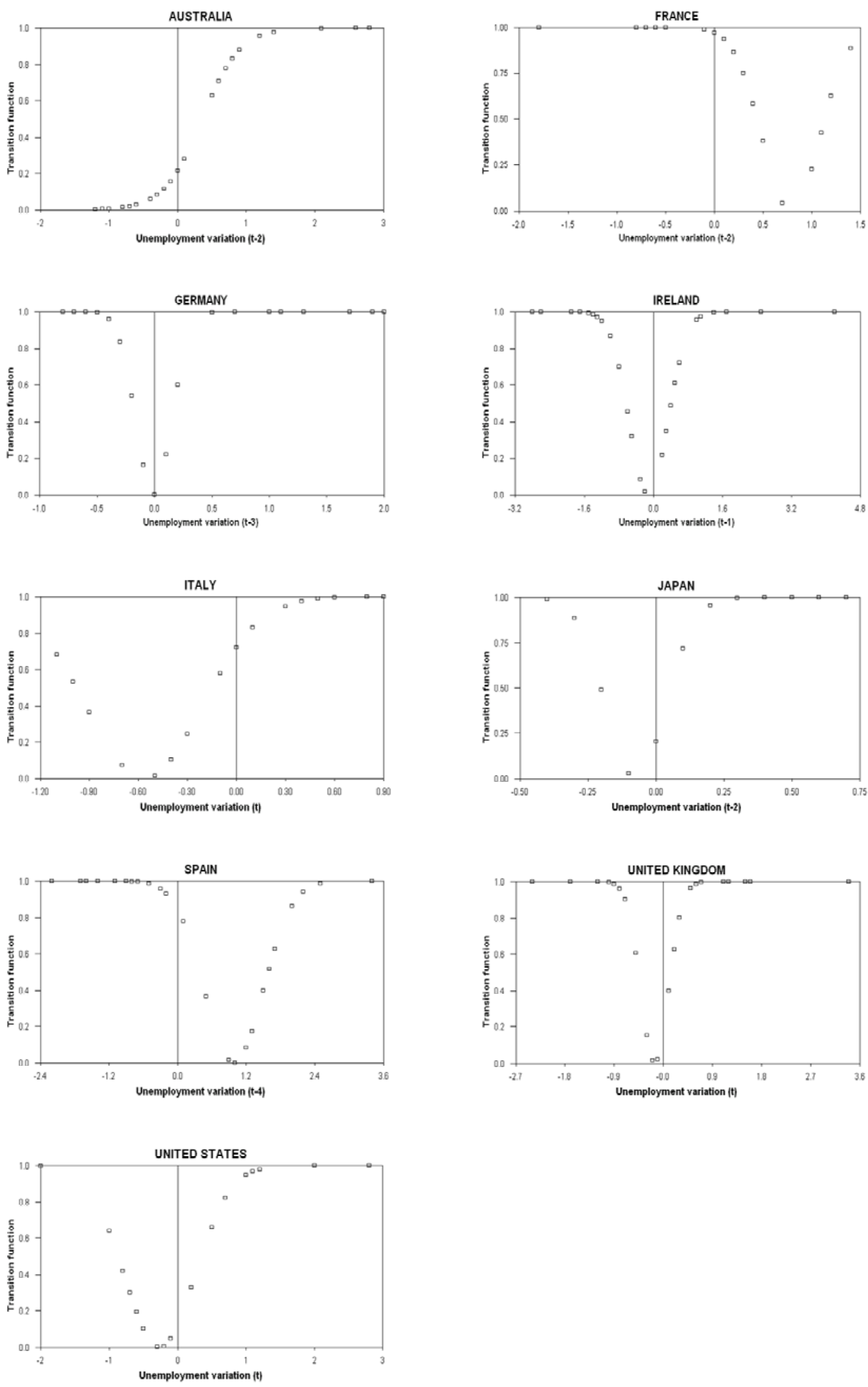


\section{DISCUSSION PAPERS I N ECONOMI CS}

2008/5 Dan Wheatley, Irene Hardill and Bruce Philp, "Managing" reductions in working hours: A study of work-time and leisure preferences in the UK industry

2008/4 Adrian Kay and Robert Ackrill, Institutional change in the international governance of agriculture: a revised account

2008/3 Juan Carlos Cuestas and Paulo José Regis, Testing for PPP in Australia: Evidence from unit root test against nonlinear trend stationarity alternatives

2008/2 João Ricardo Faria, Juan Carlos Cuestas and Luis Gil-Alana, Unemployment and entrepreneurship: A Cyclical Relation

2008/1 Zhongmin Wu, Mark Baimbridge and Yu Zhu, Multiple Job Holding in the United Kingdom: Evidence from the British Household Panel Survey

\section{SCUSSI ON PAPERS I N POLITI CAL ECONOMY}

2006/3 I oana Negru, On Homogeneity and Pluralism within Economics Schools of Thought

2006/2 David Harvie and Bruce Philp, Learning and Assessment in a Reading Group Format or Reading Capital... For Marks

2006/1 David Harvie, Bruce Philp and Gary Slater, Regional Well-Being and 'Social Productivity' in Great Britain'

2004/2 Massimo De Angelis and David Harvie, Globalisation? No Question: Foreign Direct Investment and Labour Commanded

2004/1 David Harvie, Value-Production and Struggle in the Classroom, or, Educators Within, Against and Beyond Capital

\section{DISCUSSION PAPERS IN APPLIED ECONOMI CS AND POLICY}

2007/2 Juan Carlos Cuestas, Purchasing Power Parity in Central and Eastern European Countries: An Analysis of Unit Roots and Non-linearities

2007/1 Juan Carlos Cuestas and Javier Ordóñez, Testing for Price Convergence among Mercosur Countries

2006/2 Rahmi Cetin and Robert Ackrill, Foreign Investment and the Export of Foreign and Local Firms: An Analysis of Turkish Manufacturing

2006/1 Robert Ackrill and Adrian Kay, The EU Financial Perspective 2007-2013 and the Forces that Shaped the Final Agreement

2004/5 Michael A. Smith, David Paton and Leighton Vaughan-Williams, Costs, Biases and Betting markets: New evidence

2004/4 Chris Forde and Gary Slater, Agency Working in Britain: Character, Consequences and Regulation

2004/3 Barry Harrison and David Paton, Do 'Fat Tails' Matter in GARCH Estimation? Stock market efficiency in Romania and the Czech Republic

2004/2 Dean Garratt and Rebecca Taylor, Issue-based Teaching in Economics

2004/1 Michael McCann, Motives for Acquisitions in the UK

2003/6 Chris Forde and Gary Slater, The Nature and Experience of Agency Working in Britain

2003/5 Eugen Mihaita, Generating Hypothetical Rates of Return for the Romanian Fully Funded Pension Funds

2003/4 Eugen Mihaita, The Romanian Pension Reform 
2003/3 Joshy Easaw and Dean Garratt, Impact of the UK General Election on Total Government Expenditure Cycles: Theory and Evidence

2003/2 Dean Garratt, Rates of Return to Owner-Occupation in the UK Housing Market

2003/1 Barry Harrison and David Paton, The Evolution of Stock Market Efficiency in a Transition Economy: Evidence from Romania 